\title{
Dispersive Micro Solid-Phase Extraction Using Multiwalled Carbon Nanotubes for Simultaneous Determination of Trace Metal Ions by Energy-Dispersive X-ray Fluorescence Spectrometry
}

\author{
Robert Skorek, ${ }^{a}$ Beata Zawisza, ${ }^{a}$ Eva Marguí,b Ignasi Queralt, ${ }^{\mathrm{c}}$ Rafal Sitko ${ }^{\mathrm{a}, *}$ \\ anstitute of Chemistry, University of Silesia, Szkolna 9, 40-006 Katowice, Poland \\ ${ }^{\mathrm{b}}$ Department of Chemistry, University of Girona, Campus Montilivi s/n, 17170-Girona, Spain \\ "Institute of Earth Sciences “Jaume Almera," CSIC. Solé Sabarís s/n. 08028 Barcelona, Spain
}

\begin{abstract}
A methodology based on dispersive micro solid-phase extraction (DMSPE) using multiwalled carbon nanotubes (MWCNTs) as solid sorbent prior to measurement with energy-dispersive $\mathrm{X}$-ray fluorescence (EDXRF) spectrometry is proposed. The procedure consists of chelating of nickel, cobalt, copper, and lead ions with ammonium pyrrolidinedithiocarbamate (APDC) and posterior adsorption of metal chelates on MWCNTs $(1 \mathrm{mg})$ dispersed in the aqueous samples $(100 \mathrm{~mL})$. DMSPE promotes immediate interaction between the metal chelates and MWCNTs and shortens time of sample preparation in comparison with classical solid-phase extraction. After microextraction process, MWCNTs are collected onto filter and directly measured by EDXRF. With this technique, the direct quantification of metal species held in solid materials is possible and, therefore, the elution step can be avoided. The effects of various experimental parameters such as $\mathrm{pH}$ of the solution, amounts of MWCNTs and APDC, sample volume, and time of stirring were investigated. With the best analytical conditions (1 mg of MWCNTs, 2 mg of APDC, $100 \mathrm{~mL}$ sample volume, $\mathrm{pH}=7$, and $5 \mathrm{~min}$ time of stirring), $\mathrm{Co}(\mathrm{II}), \mathrm{Ni}(\mathrm{II}), \mathrm{Cu}(\mathrm{II})$, and $\mathrm{Pb}(\mathrm{II})$ can be simultaneously determined with very good recoveries $(101 \%, 98 \%, 96 \%, 99 \%$, respectively) and detection limits $\left(0.43,0.11,0.46,0.15 \mathrm{ng} \mathrm{mL}^{-1}\right.$, respectively). The method was applied in determination of trace metal ions in tap water and wastewater samples.
\end{abstract}

Index Headings: X-ray fluorescence spectrometry; XRF; Carbon nanotubes; SPE; Preconcentration; Environmental samples; Aqueous samples; Inorganic analysis.

\section{INTRODUCTION}

Carbon nanotubes (CNTs) have received much attention in analytical chemistry due to their adsorptive properties. ${ }^{1,2}$ CNTs are used as sorbents in solid-phase extraction (SPE) both for determination organic compounds $\mathrm{s}^{3,4}$ and trace metal ions. ${ }^{5-8} \mathrm{~A}$ proper surface treatment of CNTs can enhance not only dispersibility but also improve metal sorption and selectivity. The most popular and simple modification of CNTs is the oxidation process using various acids, ozone, or plasma. Such drastic conditions lead to the opening of the tube caps and the formation of holes in the sidewalls and, in consequence, oxygen functional groups, such as $\mathrm{OH},-\mathrm{C}=\mathrm{O}$, and $-\mathrm{COOH}$ are formed. The functional groups can efficiently bind metal ions through sharing an electron pair and forming metal complexes. The raw CNTs can also be used in SPE if

Received 21 May 2012; accepted 26 September 2012.

* Author to whom correspondence should be sent. E-mail: rafal.sitko@us. edu.pl.

DOI: $10.1366 / 12-06738$ hydrophobic complexes of determined metal ions are formed. In this case, trace elements are adsorbed on raw CNTs through van der Waals forces or hydrophobic interactions. The choice of chelating agent is based on its fast reaction with metals, solubility in water, and stability in a broad $\mathrm{pH}$ range. The following chelating agents have been used in combination with CNTs: 1-(2-pyridylazo)-2-naphtol, ${ }^{9,10}$ dithizone, ${ }^{11}$ o-cresolphthalein complexone, ${ }^{12}$-hydroxquinoline, ${ }^{13}$ and ammonium pyrrolidinedithiocarbamate (APDC) ${ }^{14-16}$ Although several metal ions can successfully be determined using oxidized CNTs without chelating agent, the formation of hydrophobic complexes usually improves the analytical performance of the methodology. ${ }^{10}$

Until now SPE using CNTs as solid sorbents has been combined with spectroscopic techniques that require liquid sample to perform measurements, e.g., flame atomic absorption spectrometry, ${ }^{9-15}$ inductively coupled plasma optical emission spectrometry, ${ }^{17,18}$ inductively coupled plasma mass spectrometry, ${ }^{19,20}$ or atomic fluorescence spectrometry. ${ }^{16}$ Therefore, after the SPE extraction procedure, analytes have to be eluted using a suitable solvent. Hydrophobic complexes adsorbed on CNTs can be eluted using strongly acidic solutions, organic solvents, or their mixture, e.g., $\mathrm{HNO}_{3}$ /acetone, ${ }^{9,11,14,15} 20 \%$ $\mathrm{HNO}_{3},{ }^{16}$ or DMF. ${ }^{10}$ The elution process can be considered an error-prone step of the SPE procedure because of the incomplete recovery of the metal ions from the solid sorbent.

The present contribution proposes the combined use of preconcentration using multiwalled carbon nanotubes (MWCNTs) with energy-dispersive X-ray fluorescence (EDXRF) spectrometry for the determination of cobalt, nickel, copper, and lead at trace levels in aqueous samples. With this technique, the direct quantification of metal species held in solid materials is possible, and therefore the elution step can be avoided. Moreover, the proposed preconcentration procedure is based on dispersive micro solid-phase extraction (DMSPE), which promotes the immediate interaction between the metal chelates and MWCNTs and shortens time of sample preparation in comparison with classical SPE. The effects of various experimental parameters such as $\mathrm{pH}$ of the solution, amounts of MWCNTs and complexing agent (APDC), sample volume, and time of stirring have been investigated in order to select the best analytical conditions for analyte determination at trace levels. Finally, the developed procedure has been applied for the determination of cobalt, nickel, copper, and lead in different types of environmental water samples. 
TABLE I. Instrumental conditions of EDXRF measurements.

\begin{tabular}{lccccc}
\hline Analyte & $\begin{array}{c}\text { Analytical } \\
\text { line }\end{array}$ & $\begin{array}{c}\text { Voltage } \\
(\mathrm{kV})\end{array}$ & $\begin{array}{c}\text { Current } \\
(\mathrm{mA})\end{array}$ & Filter & $\begin{array}{c}\text { Line overlap } \\
\text { correction }\end{array}$ \\
\hline $\mathrm{Co}$ & $\mathrm{K} \alpha$ & 40 & 1.25 & $500 \mu \mathrm{m} \mathrm{Al}$ & $\mathrm{Fe} \mathrm{K} \beta$ \\
$\mathrm{Ni}$ & $\mathrm{K} \alpha$ & 40 & 1.25 & $500 \mu \mathrm{m} \mathrm{Al}$ & $\mathrm{Co} \mathrm{K} \beta$ \\
$\mathrm{Cu}$ & $\mathrm{K} \alpha$ & 40 & 1.25 & $500 \mu \mathrm{m} \mathrm{Al}$ & $\mathrm{Ni} \mathrm{K} \beta$ \\
$\mathrm{Pb}$ & $\mathrm{L} \alpha$ & 40 & 1.25 & $500 \mu \mathrm{m} \mathrm{Al}$ & \\
\hline
\end{tabular}

\section{EXPERIMENTAL}

Reagents. Element stock solutions $\left(1 \mathrm{mg} \mathrm{mL}^{-1}\right.$ of $\mathrm{Co}, \mathrm{Ni}$, $\mathrm{Cu}$, and $\mathrm{Pb}$ ), nitric acid (65\%, Suprapur $\left.{ }^{\circ}\right)$, and ammonium hydroxide solution $(25 \%$, Suprapur) were purchased from Merck (Darmstadt, Germany), and ammonium pyrrolidinedithiocarbamate $(>98 \%)$ was purchased from POCh (Gliwice, Poland). Multiwalled carbon nanotubes (MWCNTs) with diameters of 6 to $9 \mathrm{~nm}$ and lengths of approximately $5 \mu \mathrm{m}$ were purchased from Sigma-Aldrich (St. Louis, MO, USA). Before use, MWCNTs were refluxed with concentrated nitric acid and washed with high-purity water until neutral $\mathrm{pH}$ was reached, and then dried at $100{ }^{\circ} \mathrm{C}$. The suspension of MWCNTs $\left(5 \mathrm{mg} \mathrm{mL}^{-1}\right)$ was prepared using high-purity water. Before use, the MWCNTs suspension was sonicated for $30 \mathrm{~min}$ to obtain an homogeneous dispersion. The $\mathrm{pH}$ of the solutions being analyzed was adjusted with $0.1 \mathrm{~mol} \mathrm{~L}^{-1} \mathrm{HNO}_{3}$ and 0.1 mol L ${ }^{-1} \mathrm{NH}_{3} \cdot \mathrm{H}_{2} \mathrm{O}$. All reagents were dissolved and diluted with high-purity water obtained from a Milli-Q system.

Instrumentation. A touch-control S2 Ranger energydispersive X-ray fluorescence (EDXRF) system (Bruker AXS, GmbH, Germany) with a Pd X-ray tube (max. power $50 \mathrm{~W}$ ) and a Xflash ${ }^{\mathrm{TM}}$ Silicon Drift Detector (SDD) with a resolution $<129 \mathrm{eV}$ at $\mathrm{Mn}-\mathrm{K} \alpha$ was used. The instrument is also equipped with nine primary filters that can be selected for improving measuring conditions for elements of interest. One of the biggest advantages of this spectrometer compared with other existing laboratory systems is that it is equipped with an air-cooled low-power X-ray tube and a Peltier-cooled SDD, and thus no cooling media or gas consumption is required. Moreover, its compact all-in-one design with integrated PC, printer, and vacuum pump minimizes the space requirements. These facts make this system very attractive for implementation in the industry and research laboratories. Detailed information about specific features of the S2 Ranger spectrometer can be found elsewhere. ${ }^{21}$

To obtain the most efficient excitation for analyte determination, an evaluation of the best EDXRF measuring conditions was carried out. In all cases, the intensity was adjusted automatically to obtain a maximum count rate of $100000 \mathrm{cps}$, and the measuring time (200 s) was selected as a trade-off between an acceptable repeatability of measurements and total analysis time. In this study the choice of the primary beam filters and the tube operating conditions was based on the best signal-to-noise ratio attainable for each element. A combination of a primary filter made of $\mathrm{Al}(500 \mu \mathrm{m}$ thickness) and a ratio between the X-ray tube voltage and current of $40 \mathrm{kV} / 1.25 \mathrm{~mA}$ was the best option. The measurements were performed in vacuum using a $30 \mathrm{~mm}$ mask. In Table I a summary of the main instrumental conditions used is shown.

Preconcentration Procedure. The proposed extraction procedure based on dispersive micro solid-phase extraction (DMSPE) using MWCNTs was as follows: an aliquot of 100
$\mathrm{mL}$ of sample containing metal ions to be determined was placed in a $150 \mathrm{~mL}$ beaker. Then, $100 \mu \mathrm{L}$ of a $2 \%(\mathrm{~m} / \mathrm{v})$ ammonium pyrrolidinedithiocarbamate (APDC) solution and $200 \mu \mathrm{L}$ of a $5 \mathrm{mg} \mathrm{mL}^{-1}$ oxidized MWCNTs suspension were added. The $\mathrm{pH}$ of the sample was adjusted to 7 using $0.1 \mathrm{~mol}$ $\mathrm{L}^{-1} \mathrm{HNO}_{3}$ and $0.1 \mathrm{~mol} \mathrm{~L}^{-1} \mathrm{NH}_{3} \cdot \mathrm{H}_{2} \mathrm{O}$. Subsequently, the solution was stirred at $700 \mathrm{rpm}$ for $5 \mathrm{~min}$. Homogenization was immediately achieved, which promotes the interaction between the metal chelates and MWCNTs. Then the mixture was passed through a Whatman filter of $25 \mathrm{~mm}$ in diameter (Maidstone, UK) using a filtration assembly (25 mm, Sigma-Aldrich). MWCNTs (with adsorbed metal chelates) collected onto filter were dried under an infrared heater. Loaded filters were placed between two $6.0 \mu \mathrm{m}$-thick Mylar X-ray foils (supplied by Chemplex Industries, Inc., Palm City, FL, USA) mounted in special liquid sample holders, which incorporates snap-on ring at the end of the cell for attachments of thin-film supports. Afterward, samples were sealed in the sample holder of the equipment for EDXRF analysis. Blank samples were prepared using the same procedure, but an aliquot of $100 \mathrm{~mL}$ of Milli-Q water was used instead of the solution containing the target elements or natural sample of water.

Preparation of Calibration Samples. The calibration samples were prepared using the described DMPSE procedure using a series of multielement solutions containing metal ions in the concentration range 0.005 to $0.2 \mu \mathrm{g} \mathrm{mL}{ }^{-1}$. Each calibration sample was prepared in three replicates.

\section{RESULTS AND DISCUSSION}

In this paper, dispersive micro solid-phase extraction (DMSPE) using multiwalled carbon nanotubes (MWCNTs) and chelating agent (ammonium pyrrolidinedithiocarbamate [APDC]) is proposed. MWCNTs are dispersed in aqueous samples, which promote the immediate interaction between the metal chelates and MWCNTs. In order to obtain high recoveries of the metal ions on MWCNTs, several analytical parameters affecting the extraction procedure such as $\mathrm{pH}$, amount of MWCNTs and APDC, sample volume, and time of sorption process were carefully evaluated.

Effect of Sample pH. The effect of sample $\mathrm{pH}$ on adsorption of $\mathrm{Co}$ (II), $\mathrm{Ni}(\mathrm{II}), \mathrm{Cu}(\mathrm{II})$, and $\mathrm{Pb}$ (II) on MWCNTs in the presence of APDC was studied within the range of 1.0 to12.0. The experiment was performed using both raw and oxidized MWCNTs, and stirring time was set at $30 \mathrm{~min}$. As can be seen in Fig. 1, high recoveries for $\mathrm{Co}(\mathrm{II}), \mathrm{Ni}(\mathrm{II}), \mathrm{Cu}(\mathrm{II})$, and $\mathrm{Pb}$ (II) were found in the $\mathrm{pH}$ range of 6.0 to 9.0 . A pH value of 7.0 was chosen for subsequent experiments. It is interesting to note that the raw and oxidized MWCNTs gave similar results in terms of recovery values (Fig. 1). However, oxidized MWCNTs were used to perform further experiments. This choice results from the fact that the raw MWCNTs are insoluble and disperse with difficulty in aqueous samples due to strong van der Waals interactions that hamper metal sorption. The oxidation process with $\mathrm{HNO}_{3}$ significantly enhances dispersibility, and as a consequence a high recovery can be obtained for a short time during the sorption process. Moreover, the raw MWCNTs usually agglomerate due to Van der Waals force, and the specimens obtained after the filtration process are not homogeneous, which can influence the precision of metal determination. In Fig. 2, a comparison of the visual appearance of the filters loaded with raw and oxidized MWCNTs is presented. 
Co

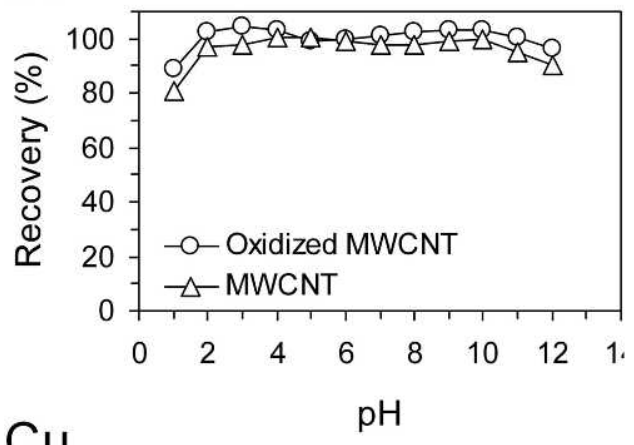

$\mathrm{Cu}$

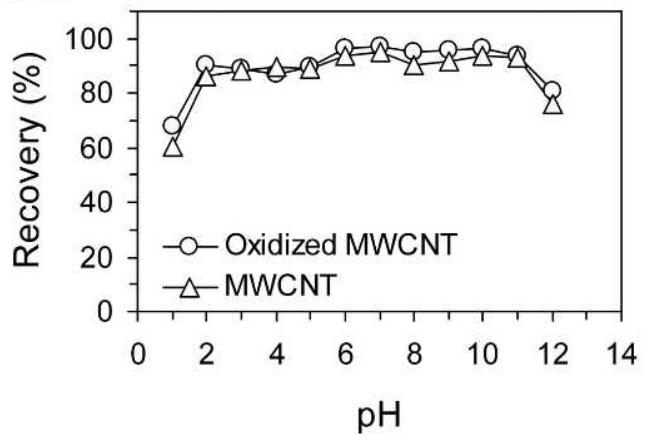

$\mathrm{Ni}$

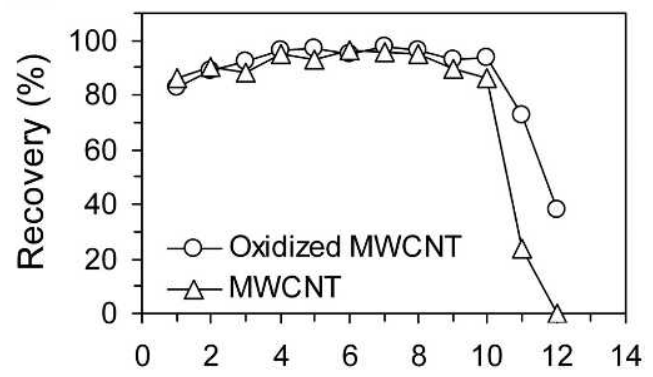

$\mathrm{Pb}$

$\mathrm{pH}$

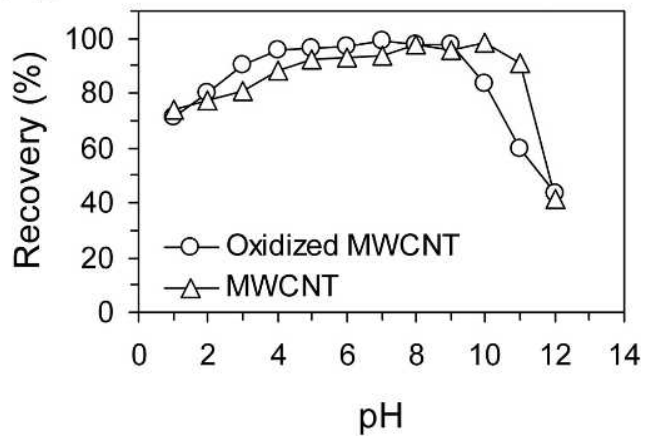

FIG. 1. Influence of $\mathrm{pH}$ on recoveries of determined elements.

Effect of Amount of Ammonium Pyrrolidinedithiocarbamate. An appropriate APDC concentration should be used to ensure an effective complexation of metal ions in the aqueous solution. The effect APDC amount on analyte recoveries was studied in the range of 0 to $0.05 \mathrm{mg} \mathrm{mL}^{-1}$ (from 0 to $5 \mathrm{mg}$ of APDC in a sample of $100 \mathrm{~mL}$ volume). As can be seen in Fig. 3, simultaneous and efficient adsorption of $\mathrm{Co}(\mathrm{II}), \mathrm{Ni}(\mathrm{II}), \mathrm{Cu}(\mathrm{II})$, and $\mathrm{Pb}(\mathrm{II})$ were achieved at APDC concentrations ranging from 0.015 to $0.05 \mathrm{mg} \mathrm{mL}^{-1}$. Satisfactory results for $\mathrm{Cu}$ (II) and $\mathrm{Pb}$ (II) were also obtained in the absence of APDC. This fact can be explained by the negative charge of oxidized MWCNTs surface at $\mathrm{pH}=7$, which causes electrostatic interactions between metal ions and

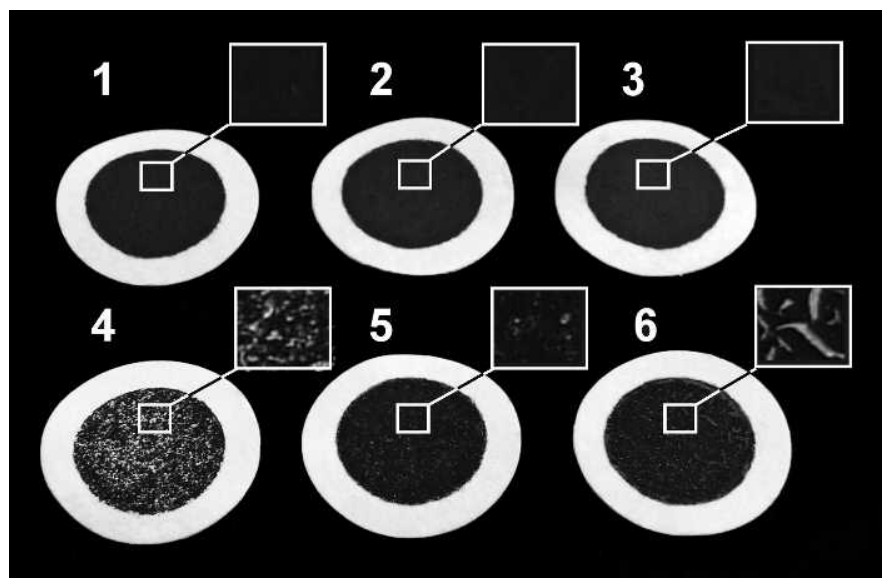

FIG. 2. Influence of MWCNTs (raw and oxidized MWCNTs) treatment on homogeneity of loaded filters. 1, 2, 3 are oxidized MWCNTs with masses of $0.5,1.5,2.0 \mathrm{mg}$, respectively; $4,5,6$ are raw MWCNTs with masses of $0.5,1.5$, $2.0 \mathrm{mg}$, respectively. oxygen functional groups $-\mathrm{COO}^{-},-\mathrm{O}$. Moreover, $\mathrm{Cu}(\mathrm{II})$ ions can be precipitated or coprecipitated at $\mathrm{pH}=7$ due to the low solubility product for $\mathrm{Cu}(\mathrm{OH})_{2}\left(\mathrm{pK}_{\mathrm{sp}}=19.3\right)$. In the presence of APDC, formation of hydrophobic complexes plays an important role. In this case, trace elements are adsorbed on MWCNTs through van der Waals forces or hydrophobic interaction. Thus, with the increase of APDC concentration, van der Waals forces or hydrophobic interactions become more important, which causes very good recoveries for $\mathrm{Co}$ (II) and $\mathrm{Ni}(\mathrm{II})$ at $\mathrm{pH}=7$. For these metal ions the recovery values increase from about $65 \%$ to $98 \%$ when increasing the APDC amount up to $0.015 \mathrm{mg} \mathrm{mL}^{-1}$. On this basis, all the studies were carried out using an APDC concentration of $0.02 \mathrm{mg}$ $\mathrm{mL}^{-1}$ (2 $\mathrm{mg}$ of APDC in the aqueous sample of $100 \mathrm{~mL}$ ). In

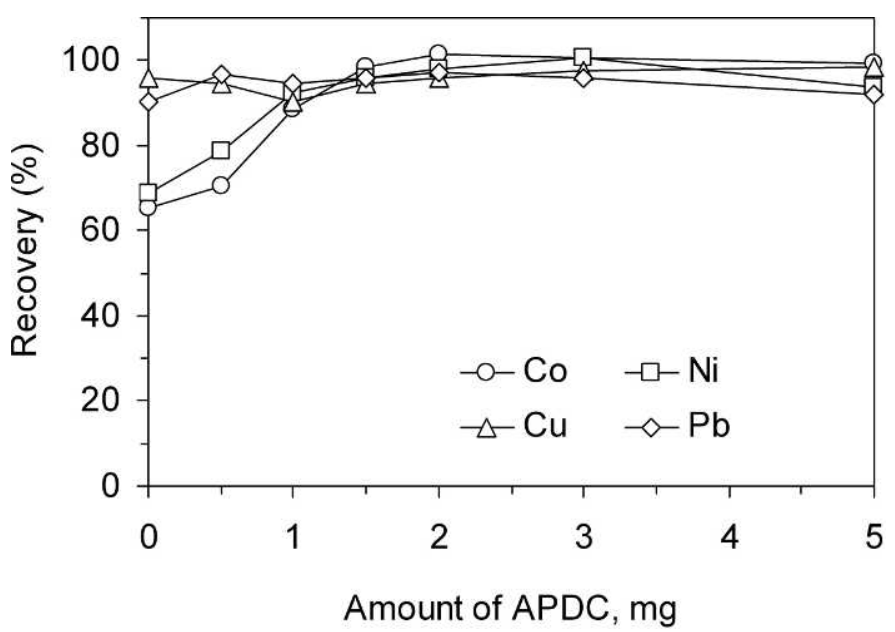

FIG. 3. Influence of APDC amount on recoveries of determined elements. 


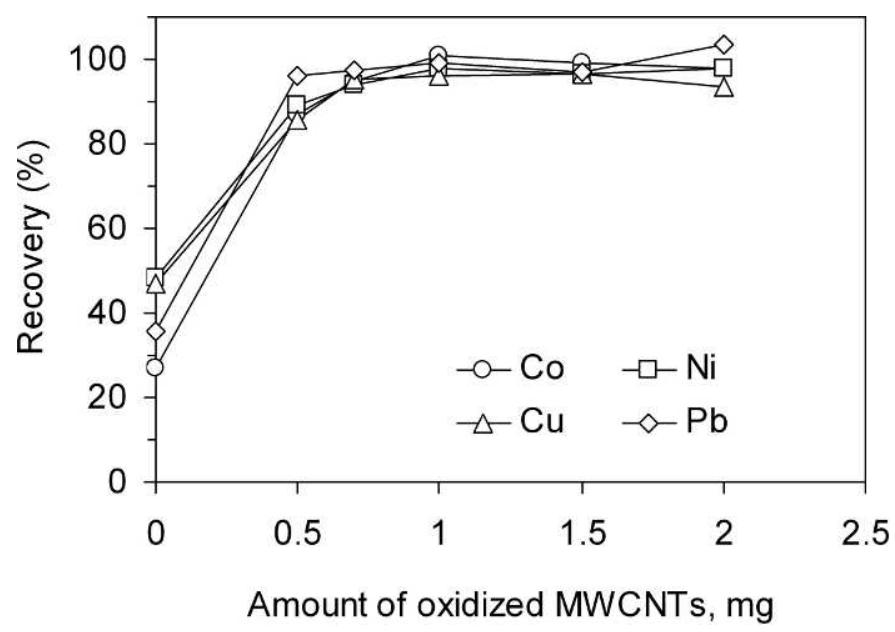

FIG. 4. Influence of MWCNTs amount on recoveries of determined elements.

this way, $\mathrm{Co}(\mathrm{II}), \mathrm{Ni}(\mathrm{II}), \mathrm{Cu}(\mathrm{II})$, and $\mathrm{Pb}(\mathrm{II})$ can be simultaneously determined at $\mathrm{pH}=7$ with very good recoveries.

Effect of Amount of Multiwalled Carbon Nanotubes. The use of an appropriate amount of the solid sorbent is also a crucial issue in DMSPE procedures because it influences the contact between the sample solution and the surface of the sorbent and in consequence on the adsorption time. The effect of MWCNTs amount on the analyte recovery values was investigated within the range of $0-2 \mathrm{mg}$ of MWCNTs. In all cases, a constant amount of $2 \mathrm{mg}$ of APDC and $100 \mathrm{~mL}$ of aqueous sample containing $0.05 \mu \mathrm{g} \mathrm{mL}^{-1}$ of metals were used. As shown in Fig. 4, metal recovery values increased with increasing MWCNT amounts up to $1 \mathrm{mg}$. Then the recovery values remain nearly constant. It also should be noted that when MWCNTs were not added to the analyzed solution the precipitation of metal chelates was also observed, which resulted in low recoveries varying in the range of $30-55 \%$. Taking into account the obtained results, further experiments were carried out adding $1 \mathrm{mg}$ of MWCNTs in $100 \mathrm{~mL}$ of the aqueous sample.

Effect of Sample Volume. Another parameter that can significantly affect the recovery values and the global sensitivity of the methodology is the volume of the aqueous

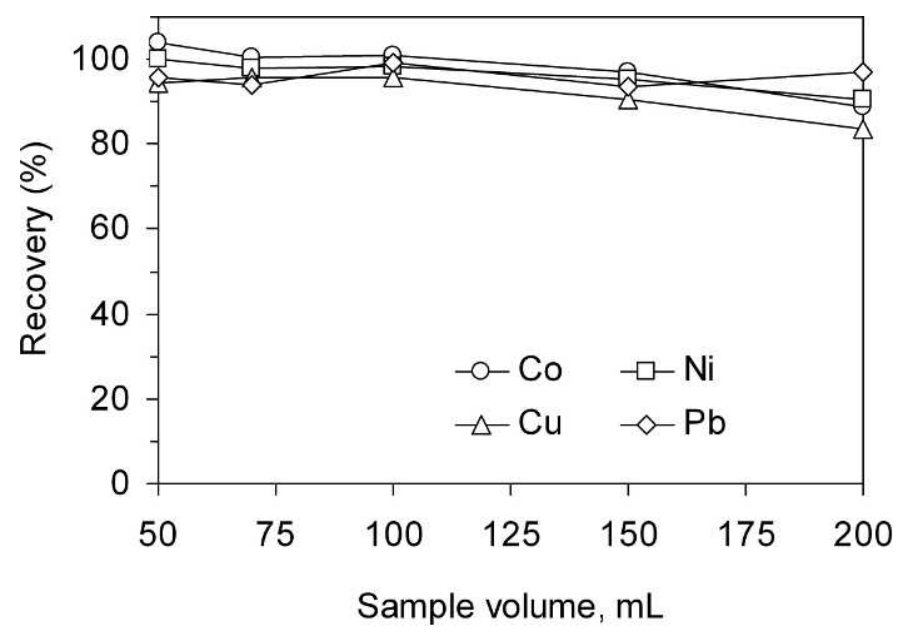

FIG. 5. Influence of sample volume on recoveries of determined elements.

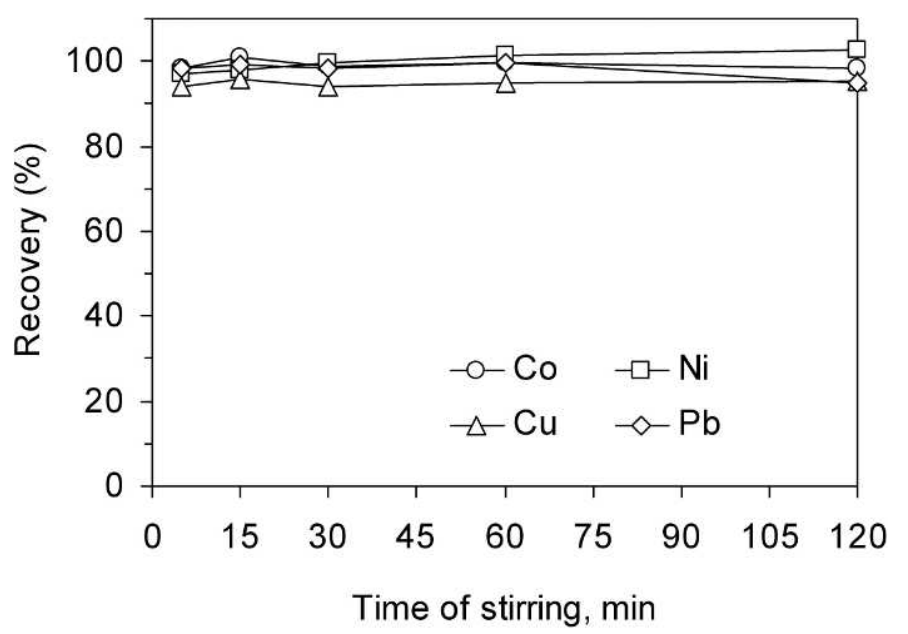

FIG. 6. Influence of stirring time on recoveries of determined elements.

sample used for preconcentration. To evaluate this effect, increasing sample volumes of the aqueous phase (from 50 to $200 \mathrm{~mL}$ ) were tested. In all cases an aqueous solution containing $5 \mu \mathrm{g}$ of $\mathrm{Co}(\mathrm{II}), \mathrm{Ni}(\mathrm{II}), \mathrm{Cu}(\mathrm{II})$, and $\mathrm{Pb}(\mathrm{II})$ was used. Quantitative recoveries were found for all the metal ions when using sample volumes up to $100 \mathrm{~mL}$ (see Fig. 5 for details). For higher volumes, a decrease of recovery values was observed for $\mathrm{Co}(\mathrm{II}), \mathrm{Ni}(\mathrm{II})$, and $\mathrm{Cu}(\mathrm{II})$. Considering multielemental analysis, $100 \mathrm{~mL}$ sample volume was set for the analysis of real samples. However, if higher volumes of aqueous sample are required (to obtain better detection limits) the amount of MWCNTs should be increased proportionately (1 $\mathrm{mg}$ of MWCNTs for $100 \mathrm{~mL}$ of aqueous sample).

Effect of Stirring Time. The time of stirring is a measure of the contact time between the sample solution and the MWCNTs. This effect on metal recoveries was investigated by varying the stirring time from 5 to $120 \mathrm{~min}$. In all cases, 1 $\mathrm{mg}$ of MWCNTs and $100 \mathrm{~mL}$ aqueous sample containing 0.05 $\mu \mathrm{g} \mathrm{mL} \mathrm{mL}^{-1}$ of metals were used. The results (Fig. 6) indicated that the time variation in the range of 5-120 min did not have a significant effect on the adsorption of the metal chelates on MWCNTs. It was found that DMSPE using MWCNTs and APDC as chelating agent promotes the immediate interaction between the metal chelates and MWCNTs. Finally, a stirring time of 5 min was chosen for further studies.

Effect of Sample Matrix. In view of the presence of coexisting ions in most environmental water samples (i.e.,

TABLE II. Influence of sample matrix on recovery (\%) of metal ions to be determined.

\begin{tabular}{lrrcr}
\hline Matrix & $\mathrm{Co}$ & $\mathrm{Ni}$ & $\mathrm{Cu}$ & $\mathrm{Pb}$ \\
\hline $20 \mu \mathrm{g} \mathrm{mL} \mathrm{m} \mathrm{Na}^{-1}, \mathrm{~K}^{+}, \mathrm{Mg}^{2+}$, & & & & \\
$\quad 100 \mu \mathrm{g} \mathrm{mL}^{-1} \mathrm{Ca}^{2+}$ & $99 \pm 5$ & $95 \pm 4$ & $97 \pm 2$ & $96 \pm 4$ \\
$50 \mu \mathrm{g} \mathrm{mL} \mathrm{Na}^{+}, \mathrm{K}^{+}, \mathrm{Mg}^{2+}$, & & & & \\
$\quad 250 \mu \mathrm{g} \mathrm{mL}^{-1} \mathrm{Ca}^{2+}$ & $95 \pm 4$ & $98 \pm 4$ & $98 \pm 3$ & $99 \pm 8$ \\
$100 \mu \mathrm{g} \mathrm{mL} \mathrm{Na}^{-1} \mathrm{Na}^{+}, \mathrm{Kg}^{++}$, & & & & \\
$\quad 500 \mu \mathrm{g} \mathrm{mL}^{-1} \mathrm{Ca}^{2+}$ & $100 \pm 6$ & $99 \pm 2$ & $99 \pm 5$ & $105 \pm 4$ \\
$200 \mu \mathrm{gL}^{-1} \mathrm{Na}^{+}, \mathrm{K}^{+}, \mathrm{Mg}^{2+}$, & & & & \\
$1000 \mu \mathrm{g} \mathrm{mL}^{-1} \mathrm{Ca}^{2+}$ & $96 \pm 4$ & $103 \pm 5$ & $95 \pm 6$ & $100 \pm 6$ \\
$0.5 \mu \mathrm{g} \mathrm{mL}^{-1} \mathrm{Fe}^{3+}, \mathrm{Al}^{3+}$ & $98 \pm 3$ & $95 \pm 6$ & $95 \pm 6$ & $96 \pm 7$ \\
$1.0 \mu \mathrm{g} \mathrm{mL}^{-1} \mathrm{Fe}^{3+}, \mathrm{Al}^{3+}$ & $94 \pm 6$ & $94 \pm 7$ & $94 \pm 5$ & $97 \pm 5$ \\
$5.0 \mu \mathrm{g} \mathrm{mL}^{-1} \mathrm{Fe}^{3+}, \mathrm{Al}^{3+}$ & $104 \pm 6$ & $93 \pm 4$ & $95 \pm 7$ & $106 \pm 8$ \\
\hline
\end{tabular}


TABLE III. Recoveries, calibration parameters and detection limits obtained under optimized experimental conditions of DMSPE + EDXRF procedure.

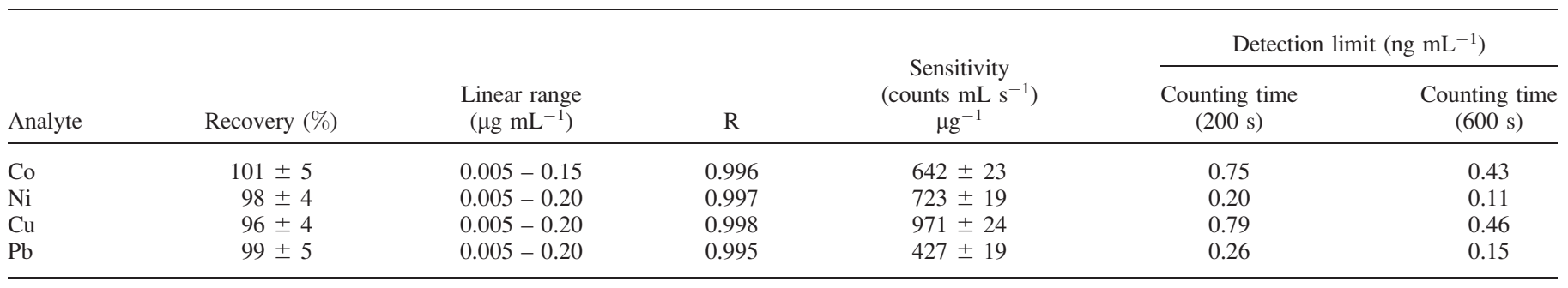

$\mathrm{Na}(\mathrm{I}), \mathrm{K}(\mathrm{I}), \mathrm{Mg}(\mathrm{II}), \mathrm{Ca}(\mathrm{II}), \mathrm{Al}(\mathrm{III}), \mathrm{Fe}(\mathrm{III}))$, it was also considered appropriate to study the influence of such compounds on the adsorption of analytes on MWCNTs using the best experimental conditions described above. The recoveries of metal ions determined in various amounts of matrix ions are given in Table II. As can be seen, the major cations that can be present in natural water have no obvious influence on the determination of the studied metal ions under the optimized conditions.

Analytical Figures of Merit of the Dispersive Micro Solid-Phase Extraction Procedure Using Multiwalled Carbon Nanotubes. In Table III, analytical figures of merit of the developed methodology, including recoveries, calibration parameters, and detection limits are displayed. As shown in Table III, $\mathrm{Co}(\mathrm{II}), \mathrm{Ni}(\mathrm{II}), \mathrm{Cu}(\mathrm{II})$, and $\mathrm{Pb}(\mathrm{II})$ can be simultaneously determined at $\mathrm{pH}=7$ with very good recoveries (96-101\%) at the working concentration levels. Under the optimized experimental conditions described above, linear ranges were observed from 0.005 up to $0.2 \mu \mathrm{g} \mathrm{mL}^{-1}$ for $\mathrm{Ni}(\mathrm{II}), \mathrm{Cu}(\mathrm{II})$, and $\mathrm{Pb}(\mathrm{II})$ and up to $0.15 \mu \mathrm{g} \mathrm{mL} \mathrm{m}^{-1}$ for $\mathrm{Co}(\mathrm{II})$. Detection limits (DL) were calculated using the following expression:

$$
\mathrm{DL}=(3 / k)(R / t)^{1 / 2}
$$

where $k$ is the sensitivity of the method in counts $\mathrm{mL} \mathrm{s}^{-1} \mathrm{ng}^{-1}$, $R$ is the background count rate in counts $\mathrm{s}^{-1}$, and $t$ is the counting time in $\mathrm{s}$.

It was found that for all of the studied elements, DLs were in the range of 0.20 to $0.79 \mathrm{ng} \mathrm{mL}^{-1}$ if a measuring time of $200 \mathrm{~s}$ was applied. However, as shown in Table III, DLs can be improved if longer measuring time is used.

Analytical Application. To test the real capability of the

TABLE IV. Analysis of tap water and spiked tap water samples (mean value \pm standard deviation, $n=3$ ) using the DMSPE + EDXRF procedure.

\begin{tabular}{lccc}
\hline Analyte & Added $\left(\mathrm{ng} \mathrm{mL}^{-1}\right)$ & Found $\left(\mathrm{ng} \mathrm{mL}^{-1}\right)$ & Recovery (\%) \\
\hline $\mathrm{Co}$ & 0 & $6 \pm 1$ & \\
& 10 & $16.6 \pm 0.4$ & 106 \\
$\mathrm{Ni}$ & 50 & $61 \pm 2.4$ & 110 \\
& 0 & $5.0 \pm 0.3$ & \\
$\mathrm{Cu}$ & 10 & $14 \pm 1.0$ & 90 \\
& 50 & $50.3 \pm 0.8$ & 91 \\
$\mathrm{~Pb}$ & 0 & $3.1 \pm 0.4$ & 99 \\
& 10 & $55 \pm 1.0$ & 104 \\
& 50 & $2.6 \pm 0.3$ & 99 \\
& 0 & $12.5 \pm 0.1$ & 104 \\
\hline
\end{tabular}

combination of DMSPE and energy-dispersive X-ray fluorescence (EDXRF) spectrometry for the intended purpose, the developed procedure was applied to the determination of $\mathrm{Co}(\mathrm{II}), \mathrm{Ni}(\mathrm{II}), \mathrm{Cu}(\mathrm{II})$, and $\mathrm{Pb}$ (II) in different types of environmental waters, including tap water and wastewater samples. In order to validate the methodology for the different types of environmental water samples, the target samples were also spiked with 10,20 , and $50 \mathrm{ng} \mathrm{mL}^{-1}$ of analytes. The recovery values of the spiked samples (Tables IV and V) were, in most cases, reasonable for trace analysis, which demonstrates the suitability of the proposed methodology for the analysis of real water samples.

\section{CONCLUSION}

Multiwalled carbon nanotubes (MWCNTs) are ideal solid sorbent to be used for preconcentration of trace metal ions prior to energy-dispersive X-ray fluorescence (EDXRF) analysis. It results not only from the excellent adsorptive properties of MWCNTs but also from the following facts:

- Multiwalled carbon nanotubes do not emit X-ray characteristic radiation (carbon and oxygen are not detected using EDXRF instruments),

- Due to the low atomic number of carbon and oxygen (in case of oxidized MWCNTs), the attenuation of X-ray fluorescent radiation of trace elements is very small,

- The particle size effects can be neglected because of the very small size of MWCNTs.

In the proposed procedure, MWCNTs are dispersed in aqueous samples, which promotes immediate interaction

TABLE V. Analysis of waste water and spiked waste water samples (mean value \pm standard deviation, $n=3$ ) using the DMSPE + EDXRF procedure.

\begin{tabular}{lrrr}
\hline \multirow{2}{*}{ Analyte } & Added $\left(\mathrm{ng} \mathrm{mL} \mathrm{mL}^{-1}\right)$ & Found $\left(\mathrm{ng} \mathrm{mL}^{-1}\right)$ & Recovery $(\%)$ \\
\hline $\mathrm{Co}$ & 0 & $22 \pm 2.4$ & \\
& 10 & $32 \pm 1.4$ & 100 \\
& 20 & $43 \pm 3.4$ & 105 \\
& 50 & $69 \pm 3.2$ & 94 \\
$\mathrm{Ni}$ & 0 & $9.0 \pm 0.5$ & \\
& 10 & $19.2 \pm 0.2$ & 102 \\
& 20 & $29.1 \pm 0.6$ & 101 \\
& 50 & $56 \pm 1.6$ & 94 \\
$\mathrm{Cu}$ & 0 & $8.8 \pm 0.7$ & 96 \\
& 10 & $18.4 \pm 0.2$ & 93 \\
& 20 & $27.3 \pm 0.2$ & 94 \\
$\mathrm{~Pb}$ & 50 & $56 \pm 4.3$ & 86 \\
& 0 & $20 \pm 2.1$ & 98 \\
& 10 & $28.6 \pm 0.2$ & 102 \\
\hline
\end{tabular}


between the metal chelates and MWCNTs, and thus the extraction procedure is very fast. It has a large advantage over the classical solid-phase extraction (SPE) procedure if high volumes of aqueous samples have to be passed through a column to obtain adequate detection limits. Moreover, EDXRF offers the possibility of direct quantification of metal species held in the solid sorbents reducing the number of chemicals required and minimizing sample handling.

The results of the present investigation show that the combination of EDXRF spectrometry with preconcentration of metal ions using MWCNTs as solid sorbent can be successfully applied for determination of trace metal ions in aqueous samples.

\section{ACKNOWLEDGMENT}

This work was supported by the Spanish National Research Program (Project ref. CGL2010-22168-C03-01).

1. M. Trojanowicz. "Analytical Applications of Carbon Nanotubes: A Review". Trends Anal. Chem. 2006. 25: 480-489.

2. M. Valcárcel, B.M. Simonet, S. Cárdenas, B. Suárez B. "Present and Future Applications of Carbon Nanotubes to Analytical Science". Anal. Bioanal. Chem. 2005. 382: 1783-1790.

3. L.M. Ravelo-Pérez, A.V. Herrera-Herrera, J. Hernández-Borges, M.T. Rodríguez-Delgado. "Carbon Nanotubes: Solid-Phase Extraction". J. Chromatogr. A 2010. 1217: 2618-2641.

4. F. Augusto, E. Carasek, R.G.C. Silva, S.R. Rivellino, A.D. Batista, E. Martendal. "New Sorbents for Extraction and Microextraction Techniques". J. Chromatogr. A 2010. 1217: 2533-2542.

5. K. Pyrzynska. "Application of Carbon Sorbents for the Concentration and Separation of Metal Ions”. Anal. Sci. 2007. 23: 631-637.

6. V.A. Lemos, L.S.G. Teixeira, M.A. Bezerra, A.C. Spínola Costa, J.T. Castro, L.A.M. Cardoso, D.S. de Jesus, E.S. Santos, P.X. Baliza, L.N. Santos. "New Materials for Solid-Phase Extraction of Trace Elements". Appl. Spectrosc. Rev. 2008. 43: 303-334.

7. K. Pyrzynska. "Carbon Nanostructures for Separation, Preconcentration and Speciation of Metal Ions". Trends Anal. Chem. 2010. 29: 718-727.

8. R. Sitko, B. Zawisza, E. Malicka. "Modification of Carbon Nanotubes for Preconcentration, Separation and Determination of Trace Metal Ions". Trends Anal. Chem. 2012. 37: 22-31.

9. H. Tavallali, V. Fakhraee. "Preconcentration and Determination of Trace Amounts of $\mathrm{Cd} 2+$ Using Multiwalled Carbon Nanotubes by Solid Phase
Extraction-Flame Atomic Absorption Spectrometry”. Int. J. Chem. Tech. Res. 2011. 3: 1628-1634.

10. S. Ghaseminezhad, D. Afzali, M.A. Taher. "Flame Atomic Absorption Spectrometry for the Determination of Trace Amount of Rhodium after Separation and Preconcentration onto Modified Multiwalled Carbon Nanotubes as a New Solid Sorbent". Talanta 2009. 80: 168-172.

11. H. Tavallali, H. Asvad. "Flame Atomic Absorption Spectrometric Determination of Trace Amounts of $\mathrm{Pb}$ (II) after Solid Phase Extraction Using Multiwalled Carbon Nanotube”. Int. J. Chem. Tech. Res. 2011. 3: $1635-1640$.

12. A. Duran, M. Tuzen, M. Soylak. "Preconcentration of Some Trace Elements via Using Multiwalled Carbon Nanotubes as Solid Phase Extraction Adsorbent". J. Hazard. Mater. 2009. 169: 466-471.

13. M. Soylak, Y.E. Unsal. "Use of Multiwalled Carbon Nanotube Disks for the SPE of Some Heavy Metals as 8-Hydroxquinoline Complexes". J. AOAC Int. 2011. 94: 1297-1303.

14. M. Tuzen, K.O. Saygi, M. Soylak. "Solid Phase Extraction of Heavy Metal Ions in Environmental Samples on Multiwalled Carbon Nanotubes". J. Hazard. Mater. 2008. 152: 632-639.

15. M. Tuzen, M. Soylak. "Multiwalled Carbon Nanotubes for Speciation of Chromium in Environmental Samples". J. Hazard. Mater. 2007. 147: 219225.

16. H. Wu, X. Wang, B. Liu, Y. Liu, S. Li, J. Lu, J. Tian, W. Zhao, Z. Yang. "Simultaneous Speciation of Inorganic Arsenic and Antimony in Water Samples by Hydride Generation-Double Channel Atomic Fluorescence Spectrometry with On-Line Solid-Phase Extraction Using Single-Walled Carbon Nanotubes Micro-Column". Spectrochim. Acta Part B 2011. 66: 74-80.

17. P. Liang, Y. Liu, L. Guo, J. Zeng, H. Lu. "Multiwalled Carbon Nanotubes as Solid-Phase Extraction Adsorbent for the Preconcentration of Trace Metal Ions and Their Determination by Inductively Coupled Plasma Atomic Emission Spectrometry". J. Anal. Atom. Spectrom. 2004. 19: 1489-1492.

18. P. Liang, Y. Liu, L. Guo. "Determination of Trace Rare Earth Elements by Inductively Coupled Plasma Atomic Emission Spectrometry after Preconcentration with Multiwalled Carbon Nanotubes". Spectrochim. Acta. Part B. 2005. 60: 125-129.

19. S. Chen, C. Liu, M. Yang, D. Lu, L. Zhu, Z. Wang. "Solid-Phase Extraction of $\mathrm{Cu}, \mathrm{Co}$ and $\mathrm{Pb}$ on Oxidized Single-Walled Carbon Nanotubes and Their Determination by Inductively Coupled Plasma Mass Spectrometry". J. Hazard. Mater. 2009. 170: 247-251.

20. S. Chen, L. Zhu, D. Lu, X. Cheng, X. Zhou. "Separation and Chromium Speciation by Single-Wall Carbon Nanotubes Microcolumn and Inductively Coupled Plasma Mass Spectrometry". Microchim. Acta 2010. 169: 123-128.

21. Bruker. "Multielement Analysis from Sodium to Uranium". http://www. bruker-axs.com/s2_ranger.html [accessed Nov 30, 2012]. 